\title{
RANCANG BANGUN ALAT BANTU 3D SCANNER
}

\author{
Rudy, Agustinus Purna Irawan dan Didi Widya Utama \\ Program Studi Teknik Mesin Jurusan Teknik Mesin Universitas Tarumanagara
}

\begin{abstract}
Abstrak: 3D scanner adalah alat Pemindai yang digunakan untuk mengscan benda kerja. 3D scanner pada umumnya digunakan dengan tangan manusia tanpa ada alat bantu. Dalam perancang akan membuat atau merancang Alat Bantu 3D scanner. Alat bantu ini berfungsi untuk mengurangi getaran dan jarak yang selalu konsisten untuk mendapatkan hasil gambar yang maksimal. Dalam perancangan ini bertujuan untuk menghasilkan desain dan gambar kerja konstruksi alat bantu yang kuat, kokoh, aman, dan efisien. Mendapatkan hasil uji 3D scanner. Mendapatkan hasil kerja dari alat yang dibuat apakah berfungsi secara optimun atau tidak. Tiga rumusan masalah diajukan dan berhubungan dengan ketiga tujuan perancangan. Proses perancangan alat bantu 3D scanner dilakukan dengan tahapan yaitu perencanaan dan penjelasan tugas/fungsi, perencanaan konsep produk(gambar kerja). Anal isis teknik hanya pada kontruksi rangka. Perancangan alat bantu 3D scanner menghasilkan gambar hasil yang optimum, dengan spesifikasi ukuran panjang 600-1500, lebar 500 dan ting gi 1800 mm. Kapasitas benda yang digunakan hanya bisa pada ukuran terbesar $800 x 800 x 800 \mathrm{~mm}$. Kontruksi rangka terbuat dari Baja dengan bahan SS41 dan plat Baja dengan tebal $6 \mathrm{~mm}$ dan $4 \mathrm{~mm}$.
\end{abstract}

Kata Kunci: 3D scanner, Desain dan perancangan Prototype, Hasil uji, analisis konstruksi, Bahan dan Dimensi

\section{PENDAHULUAN}

\section{Latar Belakang}

Scanner pertama kali ditemukan oleh Robert S. Ledley pada tahun 1943 di New York, Amerika Serikat. Alat ini digunakan untuk menghasilkan gambar tomografi dari bagian tubuh manusia, hasil scan dari alat tersebut kemudian diubah menjadi foto gambar oleh komputer didalamnya menggunakan $\mathrm{x}$-ray atau emisi positron yang didapat dari hasil pemindaian, hasil foto gambar dari alat ini kemudian digunakan membaca kelainan pada organ tubuh manusia. Alat ini dinamakan oleh Robert S. Ledley, ACTA (Automatic Computerized Transverse Axial). Nama lain dari alat ini adalah CAT scanner atau CT scanner, CAT scanner atau CT scanner seperti nama yang banyak digunakan rumah sakit pada umumnya (Adipranata dkk., 2008)

\section{Batasan Masalah}

Asumsi dan masalah yang digunakan dalam perancangan ini:

1) Perancangan alat bantu dengan jarak terdekat antara benda dengan scanner adalah $400 \mathrm{~mm}$ dan jarak terjauh adalah $1400 \mathrm{~mm}$, serta besar volume rata-rata benda maksimum adalah $500 \mathrm{~mm}$ x $500 \mathrm{~mm}$ x $500 \mathrm{~mm}$ dan minimal volume benda terkecil adalah $200 \mathrm{~mm}$ × $200 \mathrm{~mm} \times 200 \mathrm{~mm}$.

2) Alat bantu scanner ini kita gunakan sudut elevasi 60derajat. Dengan sudut pandang keatas 50derajat dan sudut pandang kebawah 10derajat.

3) Perangkat software Laser Scanner digunakan untuk digitalisasi objek 3D benda-benda pada perancangan ini.

\section{Tujuan Perancangan}

Tujuan perancangan adalah:

1) Membuat alat bantu untuk Laser 3D Scanner.

2) Mengoptimasi dan menganalisis penggunaan dari Laser 3D Scanner agar didapatkan hasil yang optimum.

\section{Manfaat Perancangan}

Manfaat perancangan adalah: 
1) Hasil perancangan eksperimen ini diharapkan dapat memberikan kontribusi ilmiah terhadap pengembangan scanner 3 dimensi dan penelitian-penelitian lebih lanjut yang lebih inovatif tentang scanner 3 dimensi.

2) Membuat alat bantu yang dapat mengoptimalkan penggunaan Laser Scanner agar penggunaan Laser Scanner lebih optimal.

3) Meningkatkan pengetahuan perancang terhadap hal-hal baru yang sangat bermanfaat bagi peneliti sendiri maupun orang lain

\section{Proses Perancangan}

Proses perancangan adalah suatu proses aktifitas atau kegiatan yang akan dilakukan setiap mahasiswa yang mengambil mata kuliah skripsi perancangan. Dalam perancangan terdiri dari 3 tahapan:

1) Konsep design

2) Perhitungan Konstruksi

3) Pembuatan model

4) Pengujian

\section{Autodesk Inventor}

Autodesk inventor adalah software otomatisasi dari mechanical desain yang memiliki kelebihan, karena menggunakan pemodelan dilihat dari segi ruang (grafik interface). Penggunaan software ini mudah untuk di pelajari bagi mechanical desainer untuk membuat sket gambar, pemodelan produk atau detail gambar kerja.

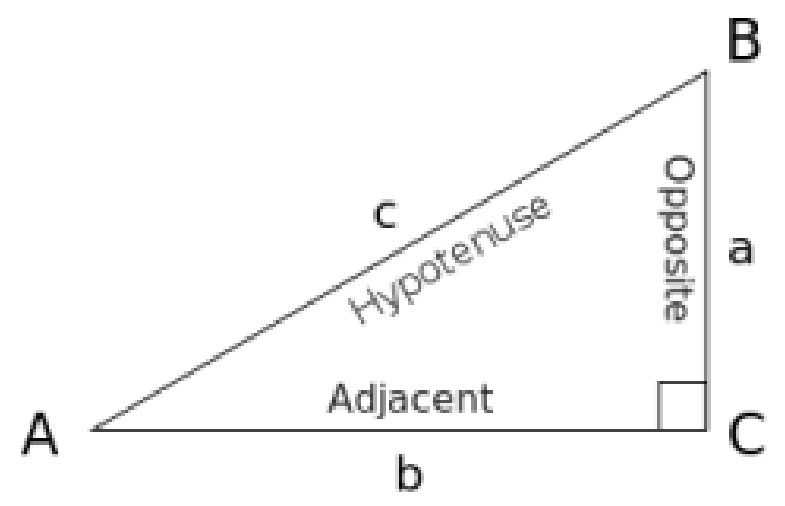

Gambar 1. Segitiga triginometri berikut.

Pada gambar di atas diberikan sudut berada pada titik B. Maka mendapatkan rumus sebagai

$$
\begin{array}{ll}
\sin \alpha=\frac{b}{c} & \operatorname{cotan} \alpha=\frac{a}{b} \\
\cos \alpha=\frac{a}{c} & \sec \alpha=\frac{c}{a} \\
\tan \alpha=\frac{b}{a} & \operatorname{cosec} \alpha=\frac{c}{b}
\end{array}
$$

\section{Rumus Perhitungan Kekuatan Pipa Baja}

$$
P_{\text {pipa }}=\sigma_{\text {bahan }} \times A_{\text {pipa }}
$$

Dimana: 
$P_{P i p a}:$ kekuatan yang dizinkan pada Pipa $(\mathrm{kg})$

$\sigma_{\text {bahan }}:$ tegangan tekan izin bahan Pipa $\left(\mathrm{kg} / \mathrm{cm}^{2}\right)$

$A_{\text {pipa }}$ : luas penampang Pipa $\left(\mathrm{cm}^{2}\right)$

- Terhadap kekuatan tanah berdasarkan konus

Dimana:

$$
Q_{\text {pipa }}=\frac{A_{\text {pipa }} \times p}{3}
$$

$Q_{\text {tiang }}:$ daya dukung Pipa $(\mathrm{kg})$

$p \quad:$ nilai konus dari hasil sondir $(\mathrm{kg} / \mathrm{cm} 2)$

3 : faktor keamanan

\section{Rumus Perhitungan Bearing}

Kekuatan Bantalan

$$
W=w \times l
$$

Besarnya momen lentur maksimum yang ditimbulkan gaya-gaya di atas adalah :

$$
M=w l / 2=W l / 2
$$

Besarnya momen tahanan lentur untuk poros lingkaran pejal adalah

$$
Z=\pi d^{3} / 32
$$

\section{Umur Bantalan}

Beban ekuivalen dinamis yaitu suatu beban yang besarnya sedemikian rupa sehingga memberikan umur yang sama dengan umur yang diberikan oleh beban dan kondisi putaran sebenarnya, dapat ditentukan dengan persamaan:

$$
P_{r}=X . V . F_{r}+Y . F_{a}
$$

Dimana:

$X$ : factor beban radial

$V$ : Beban putar pada cincin dalam

$F_{a}:$ Beban aksial

$Y:$ Faktor beban aksial

\section{Rumus Kekuatan Sambungan Las}

Kuat tarik single butt join:

$$
P=t . l \cdot f_{t}
$$

Kuat tarik double butt joint:

$$
P=\left(t_{1}+t_{2}\right) \cdot l \cdot f_{t}
$$

Dimana:

$t_{1} \quad: \quad$ tebal throat bagian atas

$t_{2} \quad$ : tebal bagian bawah 
$l \quad$ : panjang lasan

: tebal plat.

\section{METODE PERANCANGAN}

\section{Bahan dan Alat yang digunakan}

Bahan dan peralatan yang digunakan oleh perancang adalah sebagai berikut:

1. Pipa Baja dengan ukuran $96 \times 500 \times 2 \mathrm{~mm}$

2. Plat Baja dengan ukuran diameter $500 \mathrm{~mm}$ dan tebal $6 \mathrm{~mm}$

3. Pipa Baja dengan ukuran 34,5x1000x3 mm

4. Pipa Baja dengan ukuran $28,5 \times 500 \times 3 \mathrm{~mm}$

5. Bearing dengan SKF 6332 dengan diameter dalam 35mm dan diameter luar $80 \mathrm{~mm}$

6. Baut M6

7. Baut M10

8. Elektroda las dan mesin Las

9. Mesin turning

10. Mesin Drilling

11. Gerinda

12. Kunci Pas

13. Alat Scanner

14. Braket

15. Software 3D scanner Sense

\section{Metode Perancangan}

Metode yang saya gunakan dalam proses perancangan adalah dengan menggunakan sistematika diagram alir

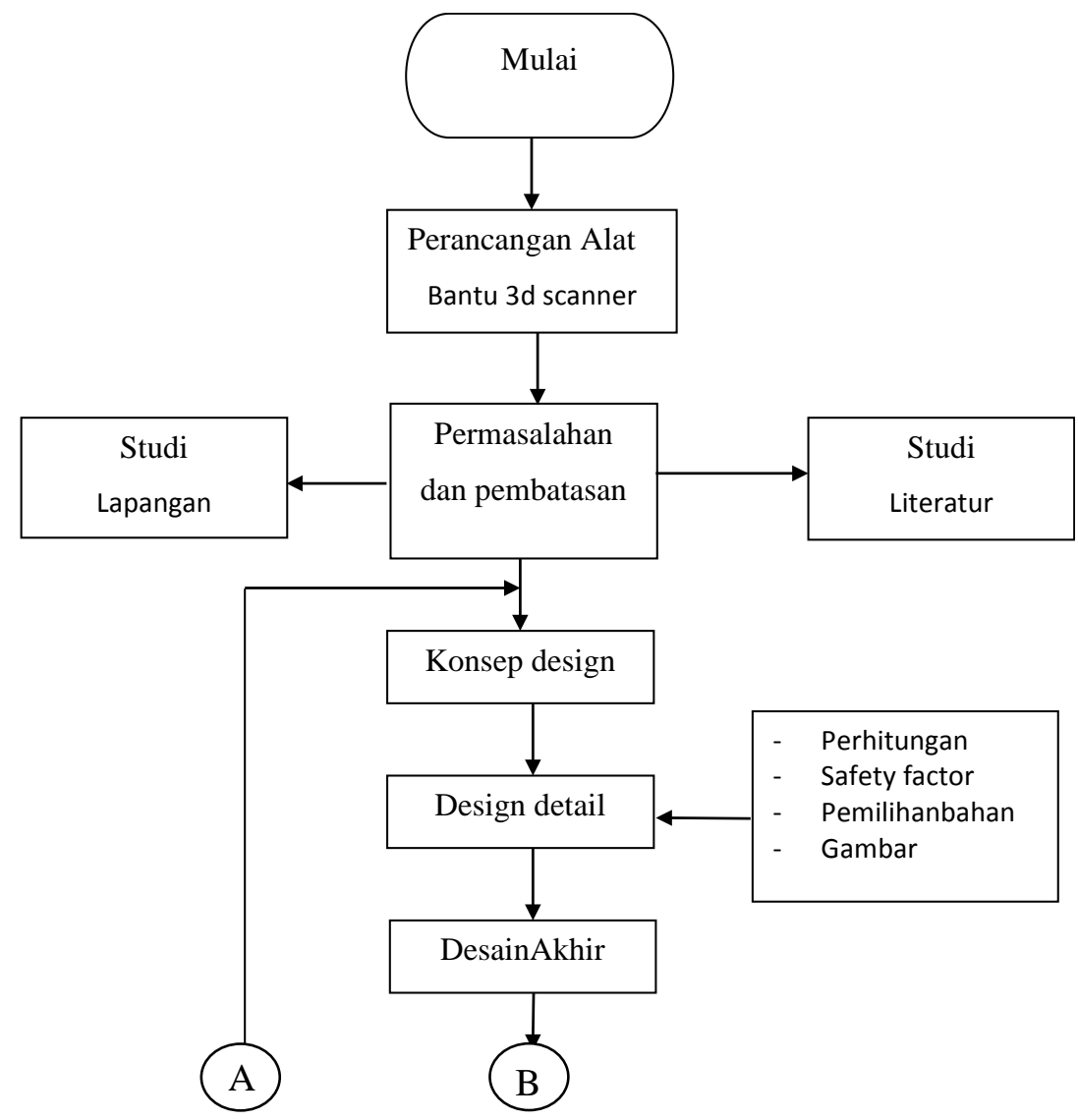

Gambar 2. Diagram alir perancangan 
Lanjutan Gambar 2. Diagram alir perancangan

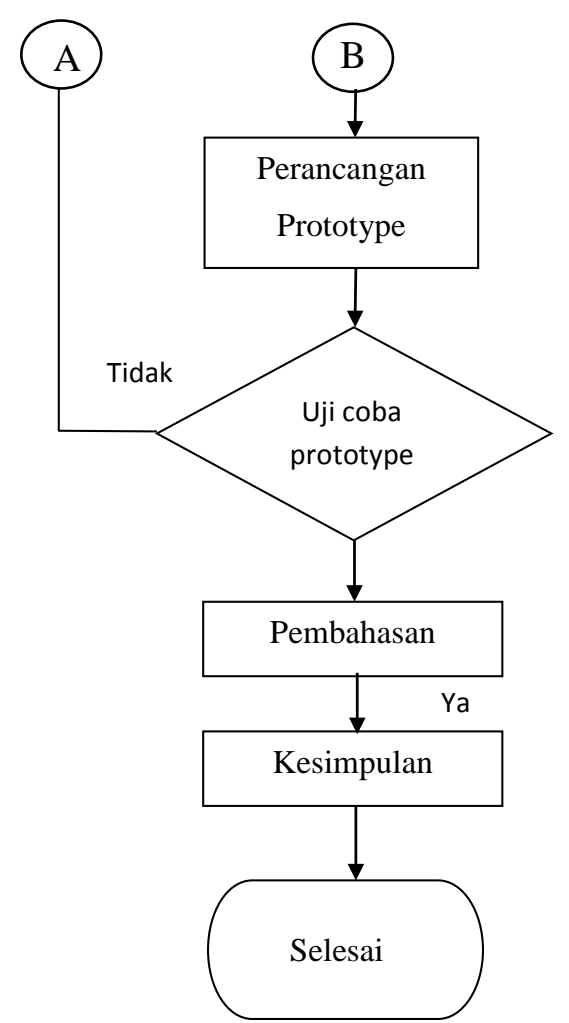

\section{HASIL DAN PEMBAHASAN}

Berdasarkan hasil perhitungan maka perancang dapat mendesain hasil perancangannya dalam bentuk 2 dimensi.

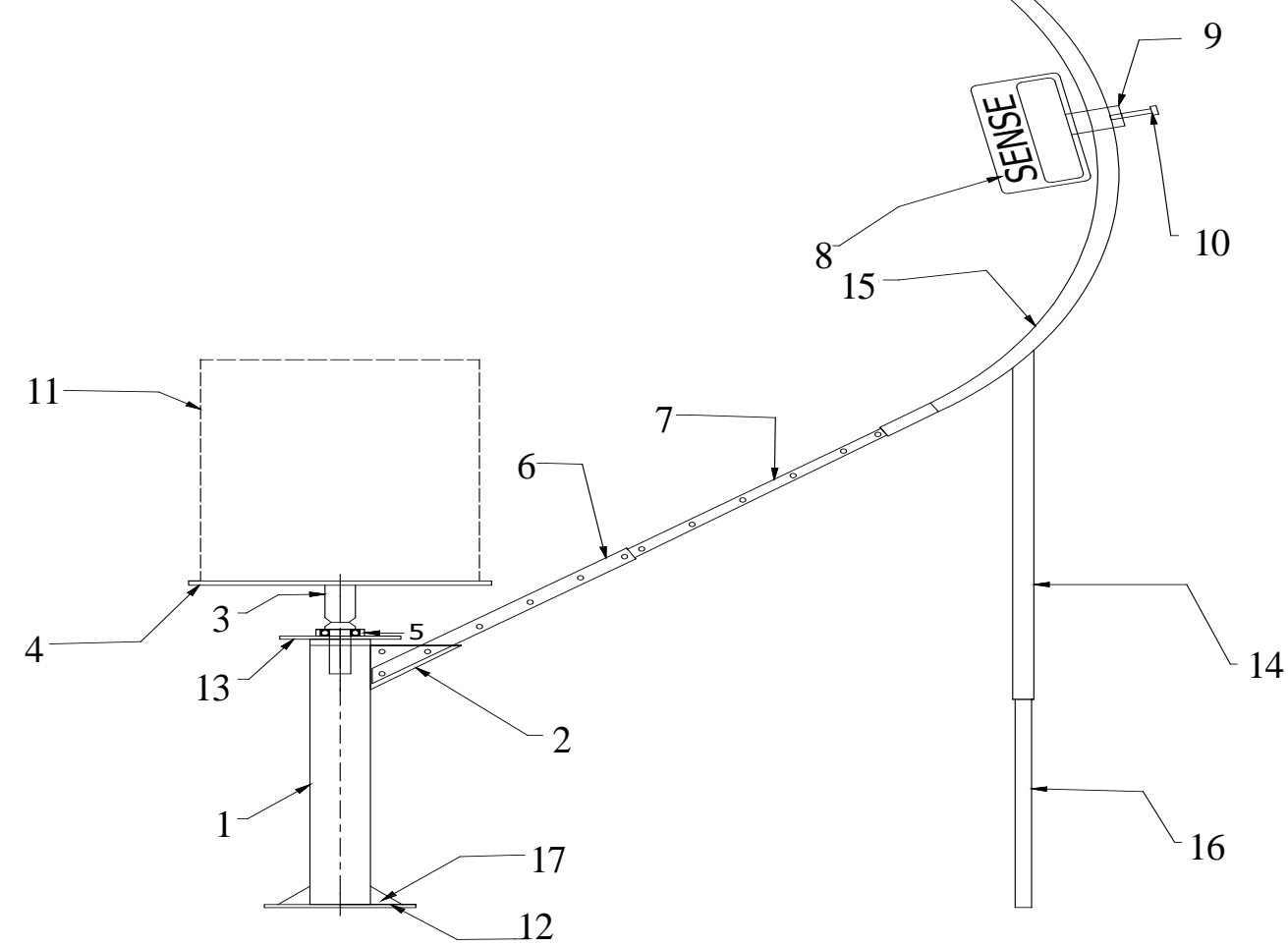

Gambar 3. Desain alat bantu 3D scanner. 
Tabel 1. Keterangan Gambar 3

\begin{tabular}{|c|c|c|c|c|}
\hline 17. & 4 & Plat baja E & ss41 & 4 \\
\hline 16. & 1 & Pipa Penyangga B & ss41 & $25 \times 4$ \\
\hline 15. & 1 & Pipa Baja D & ss41 & $35 \times 2$ \\
\hline 14. & 1 & Pipa Penyangga A & ss41 & $35 \times 2$ \\
\hline 13. & 1 & Plat baja D & ss41 & $25 \times 2$ \\
\hline 12. & 1 & Plat Baja C & ss41 & $20 \times 4$ \\
\hline 11. & 1 & Benda & & \\
\hline 10. & 7 & Baut & M10 & \\
\hline 9 & 1 & Braket & Al6010 & Aluminium \\
\hline 8. & 1 & Alat Scanner & Sense & \\
\hline 7. & 2 & Pipa baja C & st41 & silinder $25 \times 2$ \\
\hline 6. & 3 & Pipa Baja B & st41 & silinder $35 \times 2$ \\
\hline 5. & 1 & Bearing & SKF6235 & D dalam 35,Luar 80 \\
\hline 4. & 1 & Plat Baja B & ss41 & $500 \times 6$ \\
\hline 3. & 1 & Poros & fen55 & silinder \\
\hline 2. & 2 & Plat Baja A & ss41 & plat segitiga \\
\hline 1. & 1 & Pipa Baja A & $600 \times 100 \times 2$ & \\
\hline No. & Jumlah & Nama Part & Type/uk & Keterangan \\
\hline
\end{tabular}

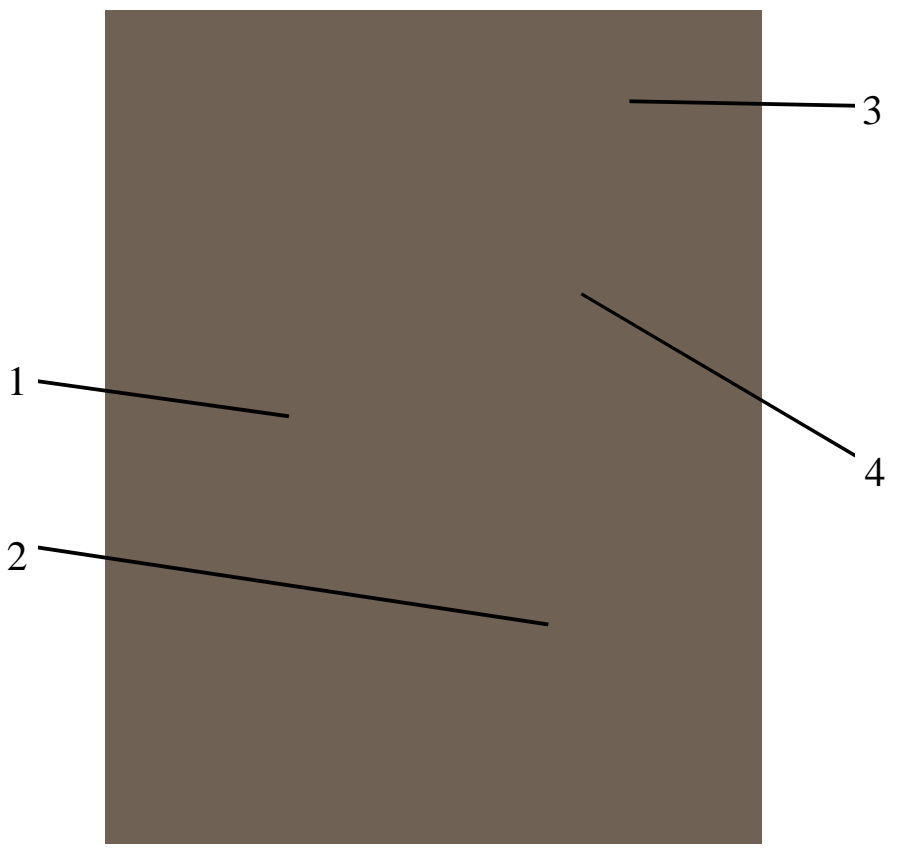

Keterangan gambar:
1. Meja kerja
2. Kaki penyangga
3. Bracket alat scanner
4. Lintasan scanner

Gambar 4. Prototype alat bantu 3D scanner

\section{Hasil Pengujian}

Dilihat dari konstruksi prototype bahwa konstruksi tersebut baik. Karena tidak terjadi getaran dan tidak terjadi goyangan dan jarak yang konsisten.

Hasil pengujian dari prototype yang dibuat,

1. Benda kecil

2. Benda sedang

3. Benda besar 


\section{Benda sedang $(40 \times 50 \mathrm{~cm})$}

Benda sedang sama pengaturan awal dengan benda kecil, hanya saja benda sedang lebih lama dibandingkan benda kecil

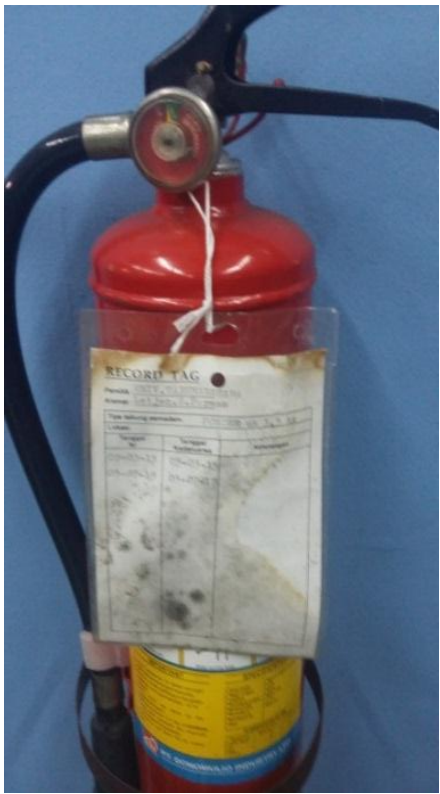

Gambar 5. Benda uji

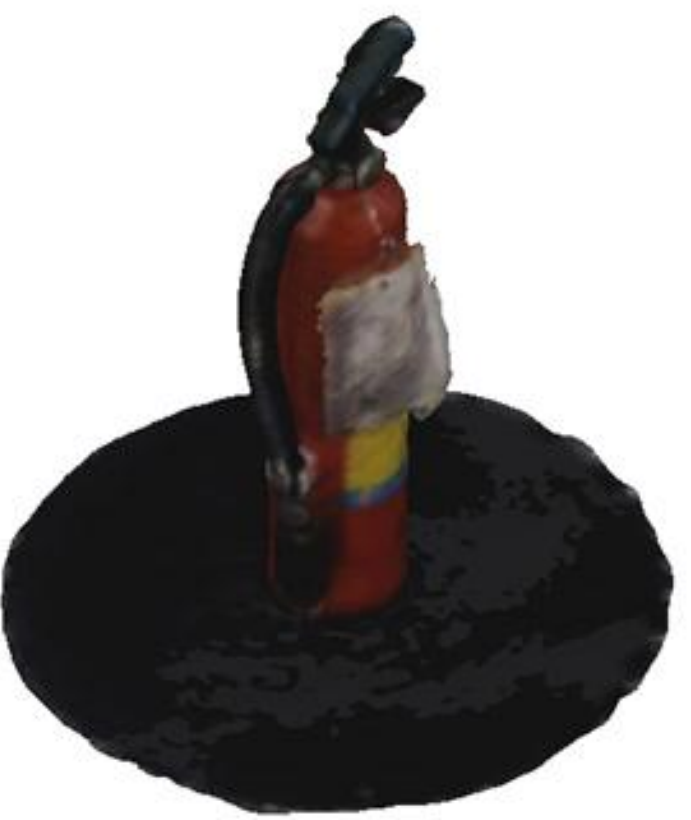

Gambar 6. Hasil scan benda uji

Dari hasil scan di atas bahwa menunjukkan alat bantu yang di buat dapat menghasilkan gambar jig yang baik.

\section{KESIMPULAN DAN SARAN}

\section{Kesimpulan}

Dari hasil perancangan serta pengujian perancang dapat menyimpulkan :

1. Benda yang akan discan harus benda yang memiliki warna solid, dalam arti benda tersebut tidak bisa Transparan, akan tetapi buka berarti benda yang Transparan tidak bisa discan, hanya saja saat scan benda yang memiliki warna transparan atau yang bersifat memantulkan cahaya, akan 
lebih sulit, dikarenakan alat scan tidak memiliki spec untuk menangkap benda yang memantul cahaya

2. Benda kecil,sedang,maupun besar memiliki pengaturan yang sama hanya saja perbedaan tempat scan itu diatur, dan memakan waktu yang berbeda pada benda masing-masing

3. Kecepatan putar benda berpengaruh sekali terhadap daya tangkap scan, karena scan tidak bisa dapat menangkap langsung benda yang berputar.

4. Alat bantu yang dibuat perancang lebih mudah digunakan karena lebih stabil dan jarak yang tetap

5. Lebih menghasilkan kualitas dan lebih cepat dibandingkan tanpa alat bantu tersebut.

6. Prototype yang dibuat sangat kokoh karena terbuat dari bahan baja, sehingga umur pemakaian jauh lebih lama.

7. Prototype bisa di bongkar pasang, sehingga tidak memakan area yang luas.

8. Benda yang akan discan bisa mencapai besar 800x800x800 mm.

\section{Saran}

1. Software scanner dengan alat scanner harus menyambung terus menerus sehingga membuat pengguna akan lebih sulit

2. Kurang nya kualitas alat scanner, sehingga perancang sulit membuat rancangannya.

3. Mekanisme putar masih manual sehingga hasil kurang maksimal, kurangnya tersebut karena kecepatan yang ada tidak stabil, karena masih menggunakan manual.

4. Tidak bisa mengscan benda kecil menggunakan alat prototype tersebut, karena memiliki jarak terdekat $800 \mathrm{~mm}$ sehingga hanya bisa benda yang minimal 300x300x300.

5. Penambahan motor pada meja agar saat berputar didapatkan kecepatan yang konstan dan tidak berubah.

\section{DAFTAR PUSTAKA}

[1]. Adipranata, Dkk. 2008. 3D Scanner. Edisi ke-1. Jakarta.

[2]. Mott, Robert L. 2004. Machine Elements in Mechanical Design. Edisi ke-4. NewJersey: Pearson Prentice Hall.

[3]. Sato, G. Takeshi. 2005. Menggambar Mesin Menurut Standar ISO. Cetakan ke-11.Jakarta: PT. Pertja.

[4]. Khurmi, R. S. dan J. K. Gupta. 2005. A Textbook of Machine Design (S.I. Units). Edisi ke-14. New Delhi: Eurasia Publishing House (PVT.) LTD.

[5]. Spesifikasi baja U diakses di situs C:/Users/user/Downloads/S1-2014-193080chapter1\%20(1).pdf. terdapat pada halaman 9, diakses tanggal 12 Februari 2016.

[6]. Sularso, dan Kiyokatsu Suga. 1987. Dasar Perencanaan dan Pemilihan Elemen Mesin. Jakarta: PT. PRANDNYA PARAMITA.

[7]. Wikipedia Bahasa Indonesia. 2014. Massa Jenis. http://www.wikipedia.com Diakses tanggal 15 Februari 2016.

[8]. http $/ /$ mesh.brown.edu/byo3d/slides/triangulation.zip

[9]. http://images- mediawiki- sites.thefullwiki.org/06/1/0/5/43784581935689675.png 